\title{
Application of Canonical Correlation for Soil -Vegetation Interrelationship in the Cocoa Belt of South Western Nigeria
}

\author{
Olusegun Ekanade, Oluwagbenga O. I. Orimoogunje*
}

Department of Geography, Obafemi Awolowo University, Ile-Ife, 220005, Nigeria

\begin{abstract}
This paper investigates the multivariate relationships between the soil and vegetation characteristics of plant communities of forest, fallow and cocoa for two reasons. The first is to bringing out the interactions among a set of independent variables and pinpoint the relative importance of each of these variables on a dependent variable be it a soil or a vegetation element. The second is to illustrate the changes that occur to the soil-vegetation properties as the tropical rainforest is cultivated to cocoa and field crops. The processes of choosing the study sites followed a random selection of sample points under three land use types: forest, fallow and cocoa (Theobroma cacao). A total of 300 sample points were selected under each of fallow and cocoa and 260 were selected under the forest. From each sample point soil samples were collected to a depth of $45 \mathrm{~cm}$ (i.e. $0-15 \mathrm{~cm} ; 15-45 \mathrm{~cm}$ ) placed into well-labelled polythene bags and taken to the laboratory for analysis. The results for the forest shows that the canonical variate of the vegetation variables account for $31 \%$ of the variance extracted by the soil factors, while the soil variables also account for $31 \%$ of the variance extracted by the vegetation variables while the result of the canonical correlation for fallow soil and vegetation extracted for the first and second canonical variates are 0.91 and 0.61 respectively. The result for the canonical correlation coefficients for cocoa for the first and second canonical variates is 0.68 and 0.51 respectively. The study concluded that while simple relationships were observed among soil and vegetation properties in the forest and fallow, complex relationships were recognised in the cocoa plant community.
\end{abstract}

Keywords Soil-Vegetation Relationship, Plant Communities, Canonical Correlation, Dependent Variables and Independent Variables

\section{Introduction}

In the tropics an increasing area is being depleted and converted to secondary forest, tree crops plantation and fallow. Many factors contribute to the forest depletion, among which are farming practices, over-exploitation of forest resources, illegal encroachment into the forest reserves and other human activities (Orimoogunje, 2005). In the case of farming whenever the forest is opened up for cultivation, the plant-soil equilibrium is disrupted. It has however, been observed that the cultivation of tree crops in the tropical rain forest region has brought a different dimension to agricultural practice and environmental conditions in the study area.

The deterioration of organic matter content of the soil under tropical cultivation has been recognized as the chief cause of decline and falling productivity of the tropical soil (Ojeniyi and Agbede, 1980; Ekanade, 1989; Kio, 2002;

* Corresponding author:

orimoogunje2@yahoo.com (Oluwagbenga O. I. Orimoogunje)

Published online at http://journal.sapub.org/re

Copyright (C) 2012 Scientific \& Academic Publishing. All Rights Reserved
Orimoogunje, 2005). Nye and Greenland (1960) and Mou tappa (1973) found that areas under fallow vegetation have less organic nutrients than areas not cultivated to crops at all. Getahun et al (2002) and Kio (2002) have also noted some correlation between the age of fallow and the amount of humus in the soil. Similar conclusions have been reached by Aweto (1981) and Areola et. al. (1982) in the forest and savannah areas of south-western Nigeria respectively. However, it has been established that soil organic matter increases as the fallow advances in age (Getahun et al, 2002). The equilibrium level is achieved as soon as the vegetal regrowth provides an adequate ground cover and generates litter comparable in quantity with what obtains in the rain forest (Nye and Greenland, 1960; Aweto, 1981). Soil is not only a means of tree anchorage, but is also a component of the nutrient and water cycle in the forest ecosystem, highly interrelated to the vegetation it supports. Hence, drastic changes in forest cover will influence soil properties, and these changes in soil properties may also influence the type of forest that can regenerate.

The objectives of this study, therefore, are to investigate the multivariate relationships between the soil and vegetation variables of plant communities of forest, fallow and cocoa in 
the study area, bring out the interactions among these variables; pinpoint the relative importance of each of these variables to others be it soil or vegetation. And lastly to illustrate the changes that occur to the soil-vegetation properties as the tropical rainforest is cultivated to cocoa and field crops utilising canonical technique.

\section{Materials and Methods}

\subsection{Study Area}

The study area covers about $800 \mathrm{~km}^{2}$ and is located in the central part of the Atakumosa Local Government Area of Osun State. It is located between latitudes $7^{0} 20^{\prime}$ and $7^{0} 38^{\prime} \mathrm{N}$ and between longitudes $4^{0} 26^{\prime} \mathrm{E}$ and $4^{0} 30^{\prime} \mathrm{E}$ (Figure 1).

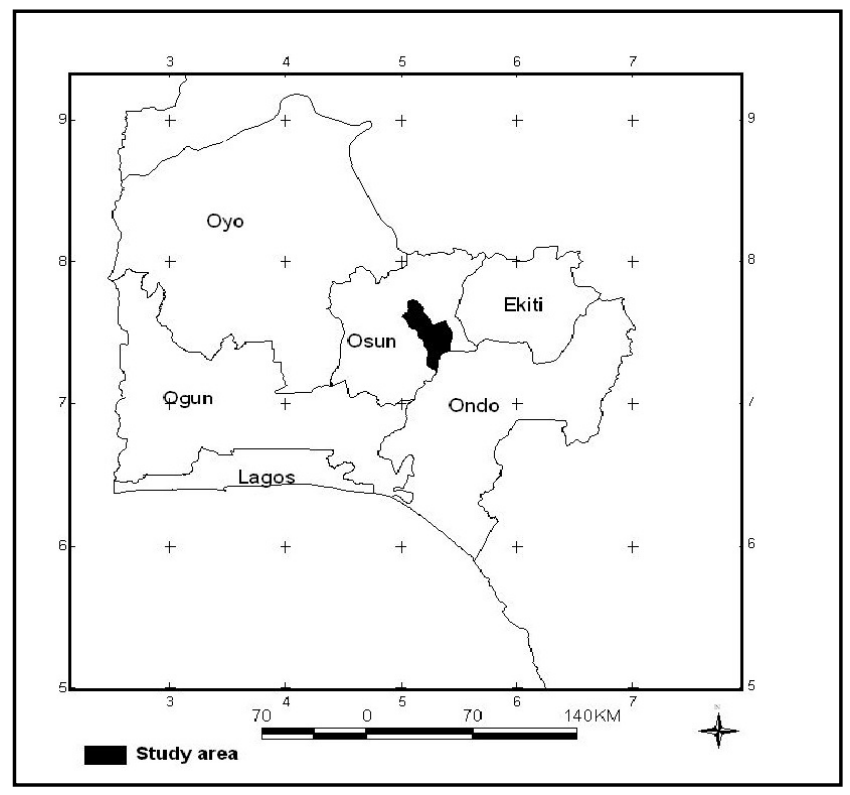

Figure 1. The Study Area

The study area is essentially rural. The climate of the area is the tropical rain forest type characterized by both high mean temperature and rainfall. The latter is about $1500 \mathrm{~mm}$ while the former is about $27^{\circ} \mathrm{C}$. However, the mean annual temperature variations rarely exceed $8^{0} \mathrm{C}$. The natural vegetation is the evergreen tropical rain forest now restricted to patches. The natural vegetation of the study area has been greatly modified by man, especially through cultivation of land resulting in a mosaic of secondary forests, fallow regrowths and tree crops. The geology of the area comprises mainly fine-grained biotite gneiss which is heavily foliated making it susceptible to deep weathering. The soils overlying the solid geology has been classified as Red Yellow Latosols, Ferruginous Tropical Soils, Alfisols and Orthic Luvisols. According to Symth and Montgomery (1962), the top $25 \mathrm{~cm}$ of the soils are usually sandy and brownish grey to brown in colour. Between depths of $25 \mathrm{~cm}$ and $120 \mathrm{~cm}$ there is a marked stone/gravel layer. The texture of this layer is rarely very clayey and may be very sandy while the colour ranges from greyish brown to reddish brown. The soils oc- cupy level to gently sloping sites at high levels in the topography and are known to be highly suitable for both food and tree crops cultivation (Adejuwon and Jeje, 1975).

\subsection{Selection of Sample Points}

The topographical maps (1:50 000) and air photos (1:40 000 ) were used to demarcate the study area and locate study sites. The process of choosing the study followed a random selection of sample points under three land use types: forest, fallow and cocoa (Theobroma cacao). A total of 300 sample points were selected under each of fallow and cocoa while 260 were selected under forest. From each sample point soil samples were collected to a depth of $45 \mathrm{~cm}$ (i.e. $0-15 \mathrm{~cm}$; $15-45 \mathrm{~cm}$ ) placed into well-labelled polythene bags and taken to the laboratory for analysis.

\subsection{Soil Analysis}

The soil samples were air-dried and sieved through 2- $\mathrm{mm}$ diameter mesh after which standard laboratory techniques were used to determine particle size distribution, moisture content, bulk density, total porosity, $\mathrm{pH}$, nitrate-nitrogen, available phosphorus, exchange calcium, magnesium, potassium and sodium, cation exchange capacity (C.E.C) and base saturation.

Bulk density and total porosity were determined by core method and particle size distribution by the hydrometer method. Soil $\mathrm{pH}$ was determined potentiometrically in $0.01 \mathrm{M}$ calcium chloride solution using a soil to calcium chloride solution ratio of $1: 2$ and organic matter was determined by the Walkley-Black method. Nitrate-nitrogen was determined by using 2, 4-phenoldisulphonic acid on the prepared soil sample solution and available phosphorus by the Bray No. 1 method. Soil samples were leached with $1 \mathrm{~N}$ neutral ammonium acetate to obtain extracts used for the determination of exchangeable cations. Thereafter, exchangeable calcium, potassium and sodium were determined by flame analyser and exchangeable magnesium by atomic absorption spectrometer. CEC was the sum of exchangeable bases and exchange acidity while percent base saturation was calculated as the sum bases divided by the CEC and multiplied by 100 .

\subsection{Litter Analysis}

Five samples of accumulated litter were collected from 0.5 $\mathrm{cm}$ square quadrats by making the five selected soil sample points from a $40 \mathrm{~m} \mathrm{x} 25 \mathrm{~m}$ plot from the centres of the quadrats. In all, 860 accumulated litter samples were collected, that is 300 from each of cocoa plantations and fallow and 260 from the mature secondary forests.

\subsection{Statistical Analysis}

The canonical correlation analysis was developed by Hotelling $(1935,1936)$ and it is designed to analyse the basic patterns of interrelationships between two sets of multivariate phenomena. The basic strategy of canonical correlation 
analysis is to derive a linear combination from each of the sets of variables in such a way that the correlation between the two linear combinations is maximized (Clark 1975; Johnston 1978). This technique has been widely applied in geographic studies (Aweto 1978; Young, 1981; Patridge and Wilson, 1989; Jafari et al. 2003; Xian-Li et al. 2008; Baize et al., 2009). Its usage in geographic research shows that canonical correlation analysis appears to be a powerful analytical tool for elucidating the basic patterns of interrelationships between two sets of multivariate data in the discipline. It is in the light of this that the technique of canonical correlation is applied in the present study to examine the pattern of interrelationships between a set of soil variables and a set of vegetation variables in the forest, fallow and cocoa plant communities.

However, it has been observed that the results of canonical correlation analysis are often difficult to interpret especially when the number of variables involved is large. Thus, preliminary data "reduction" through the use of Factor Analysis or Principal Components Analysis is usually adopted in order to make interpretation of results easier. In fact, the studies of Young (1981), Patridge and Wilson (1989), Jafari et al., (2003) and Xian-Li et al., (2008) exemplify this practice. In this study, both sets of data on soil and vegetation properties were "reduced" by the technique of Principal Components Analysis using the SPSS computer program. Furthermore, the technique of varimax rotational transformation as outlined by Harman (1970) was used to simplify the loading pattern of the variables on the components. This was done because unrotated factors are not considered to be completely diagnostic of the underlying structure in a set of data (Cattel 1965). Keskin and Yasar (2007) demonstrated that this multivariate analysis can be used to simplify the relationship between morphological and biochemical traits of the egg plant. Following the same path, Baize et. al., (2009) used it to expose the relationships between concentrations of trace metals in wheat grains and soil. Rummel (1967) and Clark (1975), among others, have identified that the varimax rotational procedure has two main advantages. These are the preservation of the total variance accounted for by the unrotated factors and the maximization of each component associated with a distinct cluster of variables. All these make interpretation of the loading pattern easier since simple structure matrix in which few variables load highly on each component results (Thurston 1936).

The changes in, and interrelationships between soil and vegetation properties under cocoa over time viz-a-viz the situation under fallow and forest were analysed using canonical correlation.

\section{Results and Discussion}

The results of the canonical correlation analysis used in this study were extracted from Principal Component Analysis performed for the data and are given in Tables 1,2 and 3 for the soil/vegetation components of the forest, fallow and cocoa plant communities respectively. Table 1 shows that only one canonical variate was extracted between soil and vegetation characteristics. The canonical correlation coefficient is 0.56 , indicating a strong relationship between the two measurement domains. Cooley and Lohnes (1971) observed that, as a rule of the thumb, any canonical correlation of 0.30 or less could be regarded as trivial. Since canonical loadings are similar to component loadings, they serve to identify the canonical variates. An examination of the canonical variate in Table 1 shows that strong relationships exist between base saturation and textural properties in the soil measurement domain and cover/litter and biomass variables in the vegetation measurement domain. The relationship between these soil variables and the cover/litter variable is positive, while that with the biomass variable is negative. This latter situation is surprising since it contradicts the general trend obtained by scholars in the simple bivariate correlation analysis (for example, Ekanade, 1989). However, it is observed that the component scores which were used as inputs for the canonical correlation analysis showed that plots which have high biomass values have large negative component scores. It can therefore, be said that this variable is negatively defined with the consequent negative relationship with the soil variables that load highly on this canonical variate. Although the organic matter component did not load highly on the canonical variate $(-0.40)$, its negative sign demands attention especially when it is considered that cover/litter component is positively defined. However, it is observed that all the plots with very high organic matter have their component scores negatively defined. In that respect, it can be conceived that the negative scores on the component of soil organic matter reacted with the positive ones for the cover/litter component to produce a misleading negative sign.

Table 1. Coefficients for canonical variables of the forest soil and vegetation

\begin{tabular}{|c|c|}
\hline Variables & Canonical variate \\
\hline Subsoil pH/soil nutrient status & 0.07 \\
\hline Textural property & $\underline{0.60}$ \\
\hline Topsoil calcium/magnesium/C.E.C & 0.36 \\
\hline Bulk density/total porosity & 0.27 \\
\hline Organic matter & -0.40 \\
\hline Base saturation & $\underline{0.72}$ \\
\hline Topsoil nitrate-nitrogen/available phos- \\
phorus/sodium/potassium & 0.01 \\
\hline Topsoil silt & -0.00 \\
\hline Subsoil available phosphorus & 0.09 \\
\hline Vegetation biomass variables & $\underline{-0.60}$ \\
\hline Cover/litter & $\underline{0.71}$ \\
\hline Density & -0.36 \\
\hline Canonical correlation coefficient & 0.56 \\
\hline Eigenvalue (squared canonical correlation) & 0.31 \\
\hline Chi-square & 32.93 \\
\hline Degrees of freedom & 27 \\
\hline Significance & 0.20 \\
\hline
\end{tabular}

Table 1 further shows the eigenvalue which is the squared value of the canonical correlation coefficient. The importance of this value is that it gives the level of variance ac- 
counted for in the soil variables by the vegetation factors and vice versa. In this canonical variate, therefore, the vegetation variables (cover/litter and biomass) account for $31 \%$ of the variance extracted by the soil factors, while the soil variables (base saturation and soil texture) also account for $31 \%$ of the variance extracted by the vegetation variables. In effect, it can be concluded that the variance accounted for by each measurement domain in the forest plant community is small. This is not surprising since it has been inferred by many scholars, when discussing the bivariate correlation analysis that as a result of the steady-state nature in the forest, low fluctuation persists between soil and vegetation since input usual almost equalizes output.

Table 2 shows the coefficients of the canonical correlation for fallow soil and vegetation. Two canonical variates were extracted and the canonical correlation coefficients for the first and second canonical variates are 0.91 and 0.61 respectively. Following the criterion of Cooley and Lohnes (1971), these canonical correlation coefficients indicate strong relationships between the two measurement domains in the fallow plant community. An examination of the structure of the canonical factor matrix as shown in Table 2 further reveals that it has the characteristics of the simple structure matrix outlined for factor analysis by Thurston (1936). The advantage of a canonical factor having a simple structure lies in the fact that it makes the interpretation of results easy. The first canonical variate indicates strong positive relationship between total porosity / $\mathrm{pH} /$ calcium / potassium / magnesium / C.E.C. and base saturation of the topsoil and cover / biomass / litter components of the vegetation. The second canonical variate also indicates a strong positive relationship between organic matter / nitrate-nitrogen of both the topsoil and subsoil and tree density components. These two canonical variates show that reciprocal relationships exist between soil and vegetation properties in the fallow plant community. This conforms to scholars findings in using simple correlation analysis for plant community studies. However, the negative sign assigned to the cover / biomass / litter component variable in the second canonical variate should be noted. It implies that this component factor is inversely related to organic matter / nitrate-nitrogen component as against what obtained between these variables in the simple bivariate correlation analysis. Again, this trend has been traced to the fact that most of the cover / biomass / litter component scores that served as inputs for the canonical correlation analysis for this factor were negatively defined thereby producing the misleading negative sign.

The eigenvalue of the first canonical variate is 0.83 while it is 0.37 for the second canonical variate. This implies that the cover/biomass/litter factor accounts for a variance of $83 \%$ in the total porosity $/ \mathrm{pH} / \mathrm{calcium} /$ potassium $/$ C.E.C/base saturation of the topsoil factor while the latter also accounts for the same amount of variance in the cover/biomass/litter factor. Similarly, tree density factor accounts for $37 \%$ of the total variance in organic matter/nitrate-nitrogen factor while a total of $37 \%$ variance in tree density factor is also ac- counted for by the organic matter/nitrate-nitrogen factor. The pattern of result for the canonical correlation analysis in the fallow plant community follows that observed in the simple bivariate correlation in which many of the soil properties are positively significantly correlated. The identification of most of the soil chemical properties, coupled with total porosity in the topsoil layer and organic matter and nitrate-nitrogen in both the topsoil layer and organic matter and nitrate-nitrogen in both the topsoil and subsoil layers as being strongly related to the vegetation properties, signifies the reciprocal relationship between soil and vegetation in the fallow plant community over time (Aweto, 1978).

Table 2. Coefficients of canonical variables of the fallow soil and vegetation

\begin{tabular}{|c|c|c|}
\hline \multirow{2}{*}{ Variables } & \multicolumn{2}{|c|}{$\begin{array}{c}\text { Canonical } \\
\text { Variate }\end{array}$} \\
\cline { 2 - 3 } & I & II \\
\hline Bulk density/sand/clay & 0.41 & -0.26 \\
\hline $\begin{array}{c}\text { Subsoil pH/organic matter/exchangeable } \\
\text { cations/C.E.C }\end{array}$ & 0.22 & -0.10 \\
\hline Organic matter/nitrate-nitrogen & 0.10 & 0.59 \\
\hline Available phosphorus & 0.27 & 0.41 \\
\hline $\begin{array}{c}\text { Topsoil total porosity/ pH calcium/ potas- } \\
\text { sium/magnesium/ C.E.C/base saturation }\end{array}$ & 0.63 & 0.35 \\
\hline Topsoil silt & 0.01 & 0.17 \\
\hline Subsoil silt & 0.16 & 0.19 \\
\hline Topsoil sodium & -0.06 & -0.01 \\
\hline Cover / biomass / litter & 0.77 & -0.64 \\
\hline Density & 0.64 & 0.77 \\
\hline Canonical correlation coefficient & 0.91 & 0.61 \\
\hline Eigenvalue (squared canonical correlation) & 0.83 & 0.37 \\
\hline Chi-square & 119.78 & 24.89 \\
\hline Degrees of freedom & 16 & 7 \\
\hline Significance & 0.00 & 0.001 \\
\hline
\end{tabular}

Table 3 shows that two canonical variates were extracted between soil and vegetation properties in the cocoa plant community. The canonical correlation coefficients for the first and second canonical variates are 0.68 and 0.51 respectively. All these indicate strong relationships between soil and vegetation properties in the cocoa plant community. It is observed that the two canonical variates have the characteristics of the simple structure matrix as in the case of fallow. The first canonical variate shows that there is strong positive relationship between bulk density/total porosity component of the cocoa soil and the density/cover/yield/weed/litter component of the cocoa vegetation. The relatively high loading of the organic matter/nutrient status component on the first canonical variate should be noted. It implies that there is also a positive strong relationship between it and the density/cover/yield/weed/litter component factor. With the exception of weed species and cocoa yield in the latter component, it seems that the sustenance of most of the topsoil properties under cocoa is undertaken by the elements of this vegetation component. In return, these vegetation prop- 
erties also have their "food supply" from the soil elements.

It appears from the result of the first canonical variate that the soil physical properties are crucial in the cocoa soil (Smyth and Montgomery 1962; Are and Gyne-Jones 1974; Falade 1975). However, the fact that the loading of the bulk density/total porosity component takes on a positive sign appears misleading. It is the other way round when the relationships between total porosity and these vegetation properties are considered. Furthermore, an examination of the component scores fed in to generate the canonical correlation does not reveal the pattern of negatively defined scores as noted in the fallow plant community. In effect, what can probably be inferred from this result is that the positive and the negative interactions of bulk density and total porosity with these vegetation properties in the cocoa plant community even out.

The second canonical variate indicates strong negative relationship between nitrate-nitrogen in the topsoil and subsoil; and subsoil exchangeable cations/C.E.C/base saturation components on the one hand and vegetation biomass component on the other (Table 3). These inverse relationships indicate that in the cocoa plant community, these soil properties appear to be adversely affected as the cocoa vegetation biomass variables increase. These results agree with the observations made by Ekanade (1989) with respect to the simple bivariate correlation analysis.

Table 3 also shows that the eigenvalues for the first and second correlation variates are 0.46 and 0.26 respectively. This means that the density/cover/yield /weed/litter component factor accounts for $46 \%$ of the total variance in bulk density/total porosity component factor while the latter also accounts for the same amount of total variance in the density/cover/yield/weed/litter component factor.

Furthermore, the biomass component factor accounts for a total variance of $26 \%$ in the subsoil exchangeable cations/C.E.C/base saturation component factors. Similarly, these latter two soil component factors account for $26 \%$ of the total variance in the cocoa vegetation biomass variable.

Table 3. Coefficients of canonical variables of the cocoa soil and vegetation

\begin{tabular}{|c|c|c|}
\hline \multirow{2}{*}{ Variables } & \multicolumn{2}{c|}{ Canonical values } \\
\cline { 2 - 3 } & $\mathrm{I}$ & $\mathrm{II}$ \\
\hline Organic matter / nutrient status & 0.43 & -0.39 \\
\hline $\begin{array}{c}\text { Subsoil exchangeable cations / C.E.C / base } \\
\text { saturation }\end{array}$ & 0.39 & -0.52 \\
\hline Bulk density / total porosity & 0.66 & -0.31 \\
\hline Sand / clay & 0.28 & 0.30 \\
\hline Available phosphorus & 0.31 & 0.26 \\
\hline Silt & -0.20 & 0.03 \\
\hline Nitrate-nitrogen & -0.02 & -0.58 \\
\hline Density / cover / yield / weed / litter & 0.99 & 0.06 \\
\hline Biomass & -0.06 & 0.99 \\
\hline Eigenvalue (squared canonical correlation) & 0.46 & 0.26 \\
\hline Chi square & 50.41 & 16.32 \\
\hline Degree of freedom & 14 & 6 \\
\hline Significance & 0.00 & 0.01 \\
\hline
\end{tabular}

The first conspicuous difference in the canonical correlation analysis between forest, on the one hand, and fallow and cocoa plant communities, on the other, is the fact that in spite of the highest number of variables used for the forest, as compared with fallow and cocoa, only one canonical variate was extracted (see Tables 1 - 3). This could probably be attributed to the steady-state in the forest as opposed to dynamic changes that are taking place in the fallow and cocoa plant communities. As evident from the discussions of the canonical correlation analysis between soil and vegetation properties in the forest, fallow and cocoa plant communities, it could be deduced that certain deteriorating changes do occur to many crucial soil physical and chemical properties under cocoa over time. It could also be inferred that tree density, foliage cover and accumulated litter appear to protect the cocoa soil, in a way, from the harsh tropical weather thereby helping to sustain its fertility to some extent.

It could be implied from the various treatments that in the forest, the influence of the steady-state condition was apparent while in the fallow, the tendency was for a reciprocal recuperative interaction between soil and vegetation over time. However, in the cocoa plant community, the analytic technique was unequivocal on the deteriorating impact of cocoa vegetation on certain crucial soil properties such as bulk density, total porosity, clay, organic matter, nitrate-nitrogen, calcium, magnesium, C.E.C. and base saturation. The above notwithstanding, it was also clearly indicated that certain elements of the cocoa vegetation appear to sustain the cocoa soil to some extent over time.

The canonical correlation indicates that increases in the cocoa biomass indices lead to deterioration in the quality of cocoa soil. This is especially so in such crucial soil chemical elements as nitrate-nitrogen, calcium, magnesium, potassium, C.E.C. and base saturation. The statistical technique indicates that two cocoa vegetation elements, foliage cover and accumulated litter, have advantageous effects on almost all of the cocoa soil elements. In effect, the maintenance of a closed canopy in the cocoa plant community may lead to greater accumulation on most elements of the cocoa soil.

\section{Conclusions}

From the outcome of the present exercise it can be concluded that while simple relationships were observed among soil and vegetation properties in the forest and fallow, complex relationships were recognised in the cocoa plant community. The study clearly indicates the steady-state nature of the forest plant community and the fact that the fallow plant community is tending towards equilibrium between soil and vegetation characteristics. The study further shows that the most affected soil properties to the extent of becoming limiting to cocoa as the latter advances in age include bulk density, total porosity, nitrate-nitrogen, calcium, magnesium, C.E.C. and base saturation. The limiting nature of these soil properties is indicated by their inverse relationships, especially in the topsoil, with the cocoa vegetation biomass and 
yield variables. The subsoil clay fractions are identified as being critical to the cocoa ecosystems, notwithstanding the age of cocoa. It could be true to conclude that the subsoil clays play a significant role in sustaining soil fertility under cocoa overtime.

\section{REFERENCES}

[1] O.O.I. Orimoogunje, The Impact of Land Use Dynamics on Oluwa Forest Reserve in Southwestern, Nigeria. Unpublished $\mathrm{PhD}$. Thesis, Department of Geography, Obafemi Awolowo University, Ile-Ife, 2005, pp.178

[2] S.O. Ojeniyi, and O.O. Agbede, Soil organic matter and yield of forest and tree crops. Plant and Soil, 1980, 57, 61-67 ekanade, O. (1989)

[3] P.R.O. Kio, Forest conservation strategies for tropical Africa. In: MacDonald, C.H. (ed.): Agro-forestry in the African Humid Tropics (United Nation University) 2002, pp. 52 - 59

[4] P.H. Nye, and D.J. Greenland, The soil under shifting cultivation. Technical Communication No. 51, Commonwealth Bureau of Soils, Harpenden, 1960

[5] F. Mouttapa, Soil aspects in the practice of shifting cultivation in Africa and the need for a common approach to soil and land resources evaluation. In: Report on the FAO/SIDA/ARCH Regional Seminar on shifting cultivation and soil conservation in Africa 1973, 31 - 35, F.A.O., Rome

[6] A. Getahun, G.F. Wilson, and B.T. Kang, The role of trees in farming system in the humid Tropics. In: MacDonald, C.H. (ed.): Agro-forestry in the African Humid Tropics (United Nation University) 2002, pp. 36 - 41

[7] A.O. Aweto, Organic matter build-up in fallow soil in a part of south-western Nigeria and its effect on soil properties. Journal of Biogeography 1981, 8, 67-74

[8] O. Areola, A.O. Aweto, and A.S. Gbadegesin, Organic matter and soil fertility restoration in forest and savanna fallows in South-western Nigeria. Geo-Journal 1982, 6, 183-192

[9] A.J. Smyth, and R.F. Montgomery, Soil and land use in central western Nigeria. Government Printer, Ibadan 1962, pp

[10] J.O. Adejuwon, and L.K. Jeje, Land element of the environmental system of Ife area, Mimeograph, Department of Geography, University of Ife, 1975, pp

[11] M. Hotelling, The most predictable criterion. Journal of Educational Psychology, 1935, 26, 139-142

[12] M. Hotelling, Relations between two sets of variates. Biometrika 1936, 28, 321-377
[13] D. Clark, Understanding canonical correlation analysis. Concepts and techniques in modern geography No. 3 Geo. Abstracts University of East Anglia, Norwich, 1975

[14] R.J. Johnston, Multivariate statistical analysis in geography. Longman, London and New York 1978

[15] A.O. Aweto, Secondary succession and soil regeneration in a part of forest zone of southwestern Nigeria. Unpublished PhD thesis, University of Ibadan, Ibadan, 1978

[16] J.E. Young, The Use of Canonical Correlation Analysis in the investigation of relationships between Plant Growth and Environmental Factors. Annals of Botany 1981 48: 811-825

[17] T.R. Partridge, and J.B. Wilson, Methods for investigating vegetation/environment relations - A Test Using the Salt Marsh Vegetation of Otago, New Zealand. New Zealand Journal of Botany, 1989, vol. 27: 35-47

[18] M. Jafari., M.A. Zare Chahouki., A. Tavili, and H. Azarnivand, Soil-Vegetation Relationships in Hoz-e-Soltan Region of Qom Province, Iran. Pakistan Journal of Nutrition 2003, 2 (6): $329-334$

[19] Xian-Li Xu' Ke-Ming Ma' Bo-Jie Fu, Cheng-Jun Song and Wen Liu, Relationships between vegetation and soil and topography in a dry warm river valley, SW China. CATENA Volume 75, Issue 2, 15 October 2008, Pages 138-145

[20] D. Baize., L. Bellanger., and R. Tomassone, Relationships between concentrations of trace metals in wheat grains and soil. Agronomy for Sustainable Development 2009, 29 (2):297-312

[21] H.H. Harman., Modern factor analysis. University of Chicago Press, Chicago 1970

[22] R.B. Cattel., The scree test for the number of factors. Multivariate Behavioural Research 1966, 1, 245-276

[23] S. Keskin, and F. Yasar, Concluded that this multivariate analysis can be used to simplify the relationship between morphological and biochemical traits of the egg plant. Pak. J. Bot., 2007, 39(5): 1547-1552

[24] R.J. Rummel, Understanding factor analysis. The Journal of Conflict Resolution 1967, XI, 444- 480

[25] L.L. Thurston, The factorial isolation of primary abilities. Psychometrika 1936, 1, 175-185

[26] W.W. Cooley, and P.R. Lohnes, Multivariate data analysis, John Wiley, New York, 1962

[27] Are, L.A. and Gwynne-Jones, D.R.G. (1974). Cacao in West Africa. Oxford University Press, Ibadan

[28] J.A. Falade, Soil bulk density-moisture supply interaction in Amazon cocoa, West African Journal of Biological and Applied Chemistry, 1975, 18, 15-22 